\section{REFERENCES}

1. Siegelman SS, Sinha SBP, Veith FJ. Pulmonary reimplantation response. Ann Surg 1973;177:30-6.

2. Rossaint R, Falke KJ, Lopez F, Slama K, Pison U, Zapol WM. Inhaled nitric oxide for the adult respiratory distress syndrome. N Engl J Med 1993;328:399-405.

3. Fullerton DA, Mitchell MB, McIntyre MC, et al. Cold ischemia and reperfusion each produce pulmonary vasomotor dysfunction in the transplanted lung. J Thorac Cardiovasc Surg 1993;106:1213-7.
4. Rimar S, Gillis N. Selective pulmonary vasodilation by inhaled nitric oxide is due to hemoglobin inactivation. Circulation 1993;88:2884-7.

5. Adatia I, Lillehei C, Arnold $\mathrm{JH}$, et al. Inhaled nitric oxide in the treatment of postoperative graft dysfunction after lung transplantation. Ann Thorac Surg 1994; 57:1311-8.

6. Zapol WM, Rimar S, Gillis N, Marletta M, Bosken CH. Nitric oxide and the lung. Am J Respir Crit Care Med 1994;149:1375-80.

\title{
PSEUDOANEURYSM OF THE BRACHIOCEPHALIC ARTERY CAUSED BY BLUNT CHEST TRAUMA
}

\author{
B. de Jose Maria, MD, ${ }^{a}$ C. Gomar, MD, ${ }^{a}$ C. Mestres, MD, ${ }^{b}$ V. Sorribes, MD, ${ }^{c}$ V. Moral, MD, ${ }^{c}$ and X. Sala, MD, ${ }^{a}$ \\ Barcelona, Spain
}

A 25-year-old man was admitted to a community hospital after a car accident with blunt chest trauma and left-sided hemopneumothorax without rib fractures. Results of laboratory tests were normal on admission, but the chest $x$-ray film showed a widened mediastinum. He was therefore transferred to our hospital. On arrival he had hemodynamic and respiratory impairment with cardiac arrest, from which he was successfully resuscitated. Computed tomography (CT) was performed and showed patent mediastinal vessels with increased density of the upper mediastinum and narrowing of the tracheal lumen. A fiberoptic bronchoscope was then inserted and showed a $50 \%$ extrinsic compression of the distal trachea. Several hours later, in the intensive care unit, the patient had a new hemodynamic impairment with edema of the neck and left arm. A second CT scan then revealed an important hematoma in the upper mediastinum and enlargement of the origin of the brachiocephalic artery. Because of suspected brachiocephalic artery rupture, emergency surgery was performed.

Once a median sternotomy approach was achieved, a contained rupture of the brachiocephalic artery from its origin to its bifurcation was made evident (Fig. 1). The injury was repaired with a $6 \mathrm{~mm}$ polytetrafluorethylene interposition graft (Fig. 2). Intraoperatively, the patient had an unexpected cardiac arrest, and when internal heart compressions were applied, a herniation of the left ventricle through a posterior pericardial rupture was detected, and was thought to be the cause of the cardiac arrest. The pericardium was sutured during resuscitation, and the operation was successfully completed. The patient

From the Departments of Anesthesiology and Cardiovascular Surgery, ${ }^{\mathrm{b}}$ Hospital Clínic de Barcelona, and the Department of Anesthesiology, ${ }^{\mathrm{c}}$ Hospital de Sabadell, Barcelona, Spain.

J Thorac Cardiovasc Surg 1995;110:863-5

Copyright (C) 1995 by Mosby-Year Book, Inc.

$0022-5223 / 95 \$ 5.00+0 \quad \mathbf{1 2 / 8 / 6 0 3 7 8}$ was discharged 20 days after the operation and 18 months later remains free of symptoms.

High-speed car accidents are the major cause of thoracic injuries resulting in disruption of the thoracic aorta and its major branches. The mechanism of injury was first described by Binet and associates ${ }^{1}$ in 1962 . They postulated that an anteroposterior force applied to the chest decreases the distance between the sternum and vertebral spine, thus displacing the heart backward and to the left. This increases the curvature of the aortic arch and stretches the vessels. The patient so injured usually hyperextends the cervical spine and rotates the head. This places further tension on the carotid artery opposite the side of rotation, resulting in an avulsion of the brachiocephalic artery from the aorta. This type of injury most often occurs at the aortic isthmus, although the brachiocephalic artery is the second most common site of vascular injury in chest trauma. In blunt trauma, the proximal artery is the more commonly injured.

It has been classically accepted that fractures of the first or second rib (or both) are an indicator of potential serious injury to adjacent neurovascular structures. ${ }^{2} \mathrm{Nev}-$ ertheless, more recent studies $^{3}$ have proved that the presence of first or second rib fractures, or even multiple rib fractures, is not associated with an increased risk of injury to the thoracic great vessels.

Even though associated injuries are common in polytrauma, cardiac or other vessel injuries are rarely associated with brachiocephalic artery disruption. ${ }^{4}$ In this case, a pericardial rupture causing cardiac herniation and intraoperative cardiac arrest was associated with a brachiocephalic artery aneurysm. Its diagnosis can be difficult, as in the case we report, in which it was overlooked and delayed until the surgical exposure of the mediastinum. Moreover, the repair of such an injury could have been fatally delayed if the operative approach had not been a median sternotomy, which enabled direct manual heart compressions. 


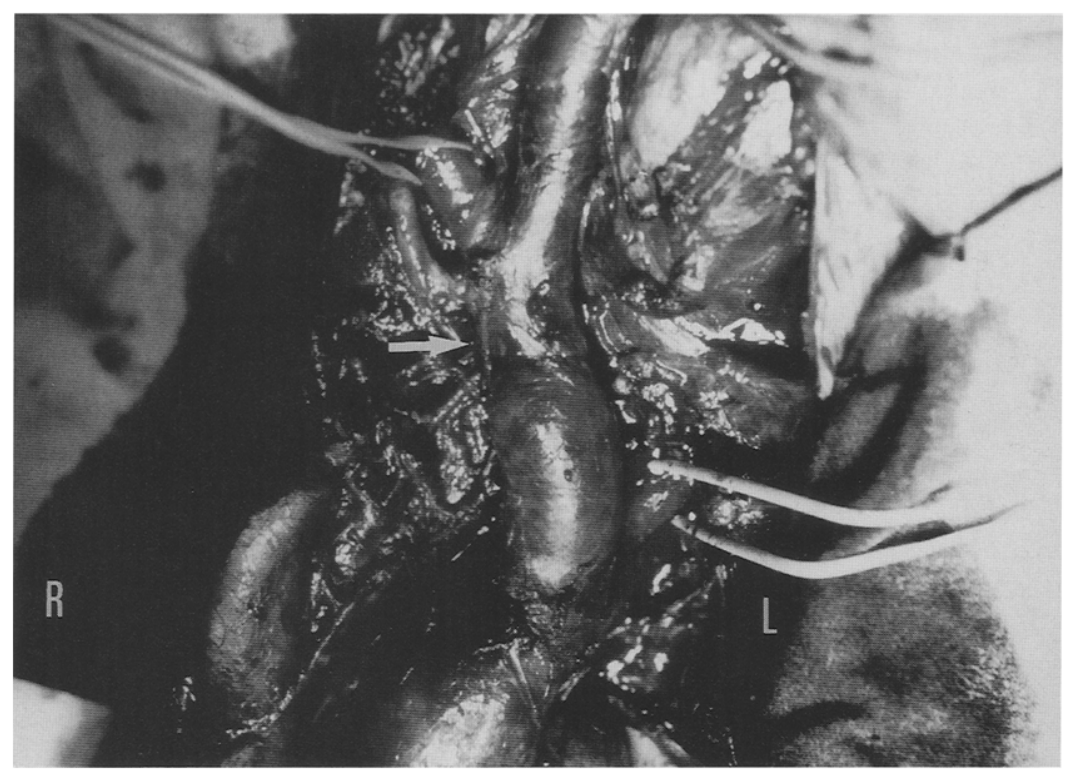

Fig. 1. Contained pseudoaneurysm of the brachiocephalic artery (arrow). Intraoperative view. $R$, Right; $L$, left.

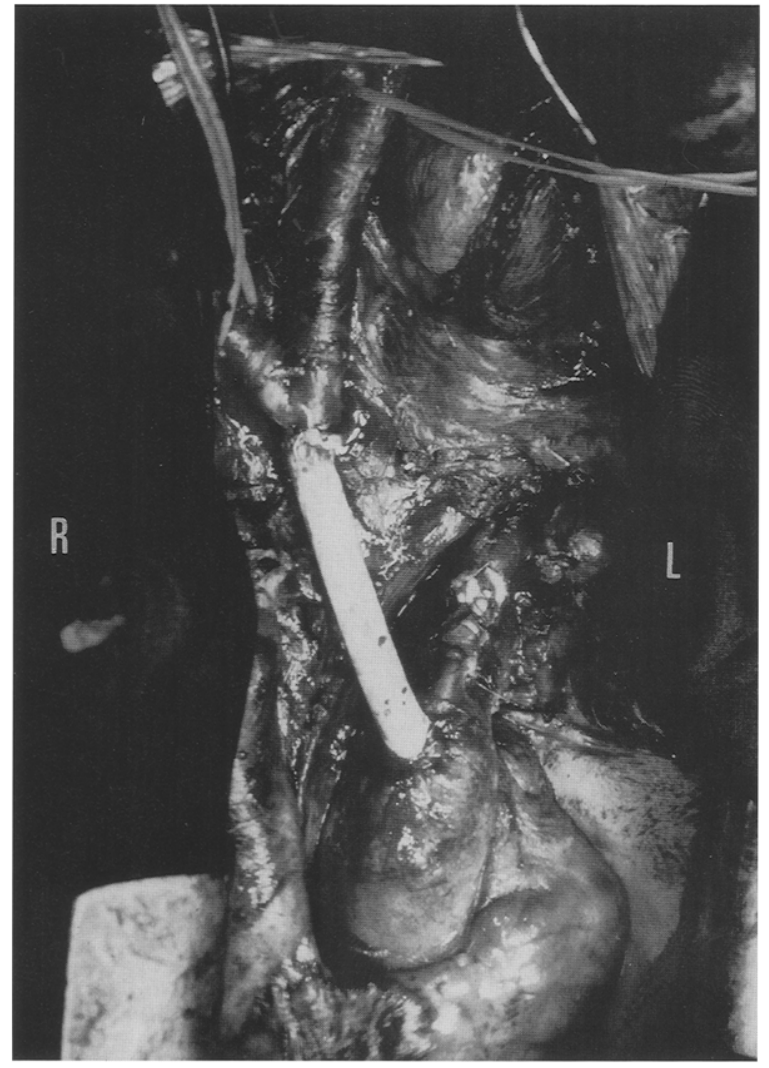

Fig. 2. Prosthetic polytetrafluoroethylene graft on the brachiocephalic artery.
Furthermore, one could believe that not only the intraoperative cardiac arrest was due to the pericardial rupture, but also the cardiac arrest on arrival in the hospital. In such a case, the pericardial rupture must have been smaller and the herniation reduced with the external heart compressions. However, once the operation was begun, with the surgical manipulation of fixed structures, the herniation became more severe and could have been fatal if the entire mediastinum had not been exposed, for instance, if another surgical approach to the vascular injury had been carried out.

Physical findings in brachiocephalic artery injuries usually are absent or nonspecific. ${ }^{5}$ Therefore a high level of awareness is needed for prompt diagnosis.

Chest roentgenography and aortic angiography are the mandatory tests to perform when a brachiocephalic artery injury is suspected. Any widening of the upper mediastinum in a patient with blunt trauma should be considered highly suggestive of mediastinal vascular injury. Angiography in the stable patient can detect clinically unrecognized injuries and can also help plan the operative approach. Furthermore, some authors ${ }^{6}$ recommend its liberal use in all stable patients who have neurologic deficits unexplained by cranial CT scan after blunt trauma.

CT scan has been helpful in detecting mediastinal hematoma but, unlike angiography, cannot define the location of the disruption of the intima. Therefore it is less important in planning the surgical repair. In the case we report, the patient's hemodynamic instability necessitated an emergency operation before angiography could be performed.

Transesophageal echocardiography could have been of great use in the diagnosis of the combined injuries in the reported case, although unfortunately this technique is still not available in the emergency departments of most hospitals. 
Because thoracic outlet vascular trauma is life-threatening owing to both exsanguination and late complications (e.g., thrombosis and aneurysms), surgical repair should be done as soon as possible with vascular anastomosis or venous or prosthetic grafts, depending on the location and type of injury. ${ }^{6}$ In some cases full or partial cardiopulmonary bypass may even be needed.

The overall survival of these patients depends on a prompt diagnosis and an aggressive surgical approach, the result of an initial awareness of the possibility of severe undiagnosed associated injuries of other intrathoracic structures. Therefore, in those cases in which unexplained hemodynamic or respiratory impairment develops after blunt chest trauma, combined thoracic vascular injuries must be suspected.

\section{REFERENCES}

1. Binet JP, Langlois J, Cormier JM, et al. A case of recent traumatic avulsion of the innominate artery at its origin from the aortic arch. J ThORAC CARDIOVASC SURG 1962;43:670-6.

2. Galbraith NF, Urschel HC, Wood RE, et al. Fracture of first rib associated with laceration of subclavian artery: report of a case and review of the literature. $\mathbf{J}$ Thorac Cardiovasc Surg 1973;65:649-52.

3. Poole GV. Fracture of the upper ribs and injury to the great vessels. Surg Gynecol Obstet 1989;169:27582 .

4. Meyer JP, Goldfaden D, Barret J, et al. Subclavian and innominate artery trauma: a recent experience with nine patients. J Cardiovasc Surg 1988;29:283-9.

5. George SM, Croce MA, Fabian TC, et al. Cervicothoracic arterial injuries: recommendations for diagnosis and management. World J Surg 1991;15:134-40.

6. McLean TR, McManus RP. Penetrating trauma involving the innominate artery. Ann Thorac Surg 1991;51: 113-5.

\title{
MODIFIED HEMI-FONTAN OPERATION AND SUBSEQUENT NONSURGICAL FONTAN COMPLETION
}

\author{
W. Konertz, MD, ${ }^{a}$ M. Schneider, MD, ${ }^{\mathrm{b}}$ V. Herwig, MD, ${ }^{\mathrm{a}}$ C. Kampmann, MD, ${ }^{\mathrm{b}}$ F. Waldenberger, MD, ${ }^{\mathrm{a}}$ and \\ G. Hausdorf, MD, ${ }^{\mathrm{b}}$ Berlin, Germany
}

Refinements in the management of patients with functional single ventricle led to the application of the Fontan principle (partial or total cavopulmonary connection) in patients whose condition is considered "nonideal" by standard criteria. ${ }^{1}$ Apart from the fenestrated Fontan operation, these include the so-called hemi-Fontan operation, the bidirectional Glenn shunt with subsequent Fontan operation, or, very recently, completion through an extracardiac conduit. ${ }^{2-4}$ All these staged procedures involve at least two operations. At the Charitè, HumboldtUniversity Berlin, we developed a procedure for a functional bidirectional Glenn operation (hemi-Fontan) with preparation for a later Fontan procedure that requires only catheter intervention to complete the Fontan repair.

Technique. The operation is performed by creating a total cavopulmonary connection with subtotal banding of the cardiac end of the superior vena cava (SVC) and incorporation of a multifenestrated lateral baffle, as in the

From the Departments of Cardiac Surgery ${ }^{a}$ and Paediatric Cardiology, ${ }^{b}$ Charitè, Humboldt-University Berlin, Berlin, Germany.

J Thorac CARdiovasc Surg 1995;110:865-7

Copyright $\mathbb{C} 1995$ by Mosby-Year Book, Inc.

$0022-5223 / 95 \$ 5.00+0 \quad \mathbf{1 2 / 5 4 / 6 3 0 6 4}$
Fontan procedure. The multifenestrated baffle can be placed during a short period of cardioplegic arrest. The baffle is constructed from a polytetrafluoroethylene prosthesis. According to the weight of the patient, five to seven $5 \mathrm{~mm}$ holes are punched in the baffle. After closure of the atrium, the aortic crossclamp is removed and the cavopulmonary connection is performed with the heart beating. The SVC is banded just above the cavoatrial junction over a 16-gauge catheter to maintain a minimal lumen for later balloon dilation. Venous blood flow from the SVC to the pulmonary vasculature is established while the venous return from the inferior vena cava enters the systemic atrium through the multifenestrated baffle (Fig. 1). Thus a bidirectional Glenn circulation is established. During the subsequent intervention, the holes in the baffle are occluded and the banded cardiac end of the SVC is reopened by balloon angioplasty.

Results. From April 1, 1994, to August 31, 1994, seven children having at least two risk factors for the Fontan operation (elevated pulmonary artery pressure, distortion of the pulmonary arteries, and regurgitant atrioventricular valves) between 2 and 13 years of age received a multifenestrated baffle and SVC banding. Mean bypass time was 97 minutes (86 to 128 minutes) and mean crossclamp time 31 minutes (19 to 79 minutes). Oxygen saturation after discontinuation of cardiopulmonary bypass was $76 \%$ 